\title{
Pre-operative to post-operative serum carcinoembryonic antigen ratio is a prognostic indicator in colorectal cancer
}

\author{
Zhenqiang Sun ${ }^{1, *}$, Fuqi Wang ${ }^{1, *}$, Quanbo Zhou ${ }^{1}$, Shuaixi Yang ${ }^{1}$, Xiantao Sun ${ }^{1}$, Guixian \\ Wang $^{1}$, Zhen Li ${ }^{1}$, Zhiyong Zhang ${ }^{1}$, Junmin Song ${ }^{1}$, Jinbo Liu ${ }^{1}$ and Weitang Yuan ${ }^{1}$ \\ ${ }^{1}$ Department of Anorectal Surgery, First Affiliated Hospital of Zhengzhou University, Zhengzhou 450052, China \\ *Co-first authors
}

Correspondence to: Zhenqiang Sun, email: zqsun82@csu.edu.cn

Weitang Yuan, email: yuanweitang@zzu.edu.cn

Jinbo Liu, email: 1999liujb@163.com

Keywords: colorectal cancer, CEA, tumor marker, prognosis

Received: April 15, $2017 \quad$ Accepted: May 05, 2017

Published: May 17, 2017

Copyright: Sun et al. This is an open-access article distributed under the terms of the Creative Commons Attribution License 3.0 (CC BY 3.0), which permits unrestricted use, distribution, and reproduction in any medium, provided the original author and source are credited.

\begin{abstract}
We explored the prognostic significance of the pre-operative-to-post-operative serum carcinoembryonic antigen (pre-post-CEA) ratio in colorectal cancer (CRC). We detected pre- and post-operative CEA levels in 2035 CRC patients surgically treated at First Affiliated Hospital of Zhengzhou University between June 2001 and June 2011. Univariate analysis revealed the pre-post-CEA ratio is associated with distant metastasis and degree of tumor differentiation (both $P<0.05$ ). Multivariate analysis showed that the pre-post-CEA ratio is associated with lymphatic and distant metastasis, tumor-node-metastasis (TNM) stage and degree of tumor differentiation (all $P<0.01$ ). The pre-CEA levels, pre-post-CEA ratios, distant metastasis, TNM stage and degree of tumor differentiation were all associated with 5 -yr overall survival (all $P<0.05$ ) based on multivariate analysis. Consequently, pre-CEA levels, pre-postCEA ratios, distant metastasis and TNM stage are independent risk factors for CRC. We have thus demonstrated that the pre-post-CEA ratio is a prognostic indicator for CRC patients.
\end{abstract}

\section{INTRODUCTION}

Colorectal cancer (CRC) is the third most commonly diagnosed cancer and the fourth leading cause of cancer death worldwide with steadily increasing mortality rates $[1,2]$. In recent years, lifestyle changes including high-fat diet, lack of exercise and mental stress has resulted in a rise in CRC cases [3]. Radical surgery still remains the best therapeutic option for CRC patients [4]. However, high recurrence and metastasis rates have resulted in poor overall survival of CRC patients [5, 6]. Therefore, identification of novel prognostic risk factors is necessary for improving survival rates.

In recent years, tumor biomarkers have been widely used in clinical diagnosis, post-operative monitoring of tumor recurrence, prognosis and curative therapy of CRC patients [7]. The serum carcinoembryonic antigen
(CEA) is one of the tumor biomarkers used for predicting recurrence, prognosis and therapeutic efficacy in CRC patients $[8,9]$. The potential clinical use of changes in pre-operative and post-operative CEA levels (pre-postCEA) has been recognized in few cancer studies $[10,11]$. Increased serum CEA levels were observed after radical surgery in some patients $[12,13]$. The significance of preand post-operative CEA levels is controversial. Hotta et al. reported that the pre-post-CEA ratio is prognostic predictor after surgery for stage III rectal cancer patients [10]. However, another study reported that post-operative serum CEA (post-CEA) levels were more definitive as prognostic prediction than pre-post-CEA ratios in nonsmall cell lung cancer patients. Therefore, in this study, we explored the prognostic relevance of pre-post-CEA ratios in predicting the survival time of $\mathrm{CRC}$ patients after radical surgery. 


\section{RESULTS}

\section{Selection strategy of research objects}

After screening 2833 CRC patients, we excluded the following: (1) unresectable (628 cases); (2) combined with other cancers (27 cases); (3) benign disease (94 cases); (4) pregnancy (2 cases); (5) emergency (24 cases) and (6 cases) untreatable due to widespread metastasis (23 cases). Finally, we enrolled 2035 patients including 1138 males and 897 females; of these, 872 had colon cancer and 1163 had rectal cancer (Figure 1).

\section{Univariate analysis of correlation between pre-CEA levels and pre-post-CEA ratios with clinicopathological parameters of CRC patients}

The patients were divided into low and high expression groups based on pre-CEA levels and prepost-CEA ratios based on their mean values. Univariate analysis showed that pre-CEA levels were associated with smoking, tumor size, lymphatic and distant metastases and TNM stage $(P<0.05$ for all parameters; Table 1). The pre-post-CEA ratios were associated with distant metastasis and degree of tumor differentiation (both $P<0.05$; Table 1). Pre-CEA levels were not associated with gender, age, family history, tissue type, degree of tumor differentiation and tumor location. Meanwhile, pre-post-CEA ratios were not associated with gender, age, family history, smoking, tumor size, lymphatic metastasis, TNM stage, tissue type and tumor location (all $P>0.05$ ).

\section{Multivariate analysis of the correlation between pre-CEA levels and pre-post-CEA ratios with clinicopathological parameters of CRC patients}

Multivariate analysis showed that pre-CEA levels were associated with family history, smoking, tumor size, distant metastasis and TNM stages (all $P<0.05$; Table 2). However, they were not associated with other cancer in combination, lymphatic metastasis, tissue type, general tumor type, degree of tumor differentiation and tumor location (all $P>0.05$ ). Meanwhile, pre-post-CEA ratios were associated with lymphatic and distant metastases, TNM stage and degree of tumor differentiation (all $P<0.01$; Table 2). But, they were not associated with family history, smoking, other cancer in combination, tumor size, tissue type, general tumor type and tumor location (all $P>0.05$ ).

\section{Univariate analysis of the correlation between pre-CEA levels and pre-post-CEA ratios with 5-year OS}

As shown in Table 3, univariate analysis demonstrated that pre-CEA levels, pre-post-CEA ratios, tumor size, TNM stage, lymphatic metastasis, distant metastasis and degree of tumor differentiation were associated with 5-year overall survival (OS, all $P<0.05$ ). Factors like age, gender, family history, smoking, tissue type and tumor location were not related with 5-year OS (all $P>0.05$ ).

\section{Multivariate analysis of the correlation between pre-CEA levels and pre-post-CEA ratios with 5-year OS}

Multivariate survival analysis showed that preoperative CEA, pre- to post- operative CEA ratio, distant metastasis, TNM stage and degree of tumor differentiation were associated with 5-year OS (all $P<0.05$, Table 4). Meanwhile, gender, age, family history, smoking, tumor size, lymphatic metastasis, tissue type, general tumor type and tumor location were not associated with 5-year OS (all $P>0.05$, Table 4). Therefore, our analysis demonstrated that pre-CEA levels, pre-post-CEA ratios, distant metastasis, TNM stage and differentiation degree were independent risk factors for 5-year OS of CRC patients.

\section{Kaplan-Meier analysis of association of overall survival with pre-CEA levels and pre-post-CEA ratios}

Kaplan-Meier survival curve analysis showed that overall survival decreased post-operatively (Figure 2). Interestingly, patients with low pre-CEA levels demonstrated survived longer than those with high pre-CEA levels (log-rank test, $P<0.001$; Figure 3 ). Meanwhile, patients with a lower pre-post-CEA ratios survived longer compared to those with higher pre-postCEA ratios (log-rank test, $P<0.001$; Figure 4). Also, patients with low pre-CEA levels and pre-post-CEA ratios (group 1) showed longer survival than patients with high pre-CEA levels and pre-post-CEA ratios (group 2). However, patients with lower pre-CEA levels, but high pre-post-CEA ratios (group 3) and patients with higher pre-CEA levels and low pre-post-CEA ratios (group 4) showed no differences with overall survival (log-rank test, $P>0.05$ ). Also, patients in groups 3 and 4 showed lower OS than group 1 patients and higher OS than group 2 patients (log-rank test, both $P>0.05$; Figure 5). This suggested that the pre-CEA levels and pre-post-CEA ratios had a synergistic effect in prognostic prediction of overall survival of CRC patients.

\section{DISCUSSION}

Carcino-embryonic antigen (CEA) represents a group of macromolecular acid glycoproteins expressed highly during fetal development and reduced in the adults $[14,15]$. High CEA levels were first observed in colorectal cancer and then in other malignant tumors of 
Table 1: Univariate analysis of relationship between pre-CEA levels and pre-post-CEA ratios with clinicopathological parameters of CRC patients

\begin{tabular}{|c|c|c|c|c|c|c|c|c|c|}
\hline \multirow{2}{*}{$\begin{array}{l}\text { Clinicopathologic } \\
\text { characteristics }\end{array}$} & \multirow[t]{2}{*}{$n$} & \multicolumn{2}{|c|}{ Pre-CEA expression } & \multirow[t]{2}{*}{$\mathbf{X}^{2}$} & \multirow[t]{2}{*}{$P$ value } & \multicolumn{2}{|c|}{ Pre-post-CEA ratio } & \multirow[t]{2}{*}{$X^{2}$} & \multirow[t]{2}{*}{$P$ value } \\
\hline & & Low & High & & & Low & High & & \\
\hline Gender & & & & 0.85 & 0.357 & & & 1.381 & 0.240 \\
\hline Male & 1138 & 467 & 671 & & & 303 & 863 & & \\
\hline Female & 897 & 350 & 547 & & & 206 & 663 & & \\
\hline Age (Years) & & & & 5.562 & 0.180 & & & 0.005 & 0.943 \\
\hline$\geq 60$ & 1091 & 412 & 679 & & & 250 & 737 & & \\
\hline$<60$ & 944 & 405 & 539 & & & 264 & 784 & & \\
\hline Family history & & & & 3.504 & 0.610 & & & 0.839 & 0.36 \\
\hline Yes & 173 & 81 & 92 & & & 68 & 179 & & \\
\hline No & 1862 & 736 & 1126 & & & 444 & 1344 & & \\
\hline Smoking & & & & 4.016 & 0.045 & & & 0.508 & 0.476 \\
\hline Yes & 426 & 153 & 273 & & & 122 & 337 & & \\
\hline No & 1609 & 664 & 945 & & & 393 & 1183 & & \\
\hline Tumor size (cm) & & & & 4.509 & 0.034 & & & 0.624 & 0.429 \\
\hline$\geq 5 \mathrm{~cm}$ & 1288 & 378 & 622 & & & 273 & 832 & & \\
\hline$<5 \mathrm{~cm}$ & 817 & 439 & 596 & & & 244 & 686 & & \\
\hline Lymphatic metastasis & & & & 5.554 & 0.018 & & & 0.200 & 0.655 \\
\hline Yes & 964 & 361 & 603 & & & 238 & 687 & & \\
\hline No & 1071 & 456 & 615 & & & 276 & 834 & & \\
\hline Distant metastasis & & & & 179.119 & $<0.001$ & & & 40.936 & $<0.001$ \\
\hline Yes & 615 & 111 & 504 & & & 140 & 224 & & \\
\hline No & 1420 & 706 & 714 & & & 374 & 1297 & & \\
\hline TNM stage & & & & 90.384 & $<0.001$ & & & 1.220 & 0.269 \\
\hline $\mathrm{I} / \mathrm{II}$ & 641 & 355 & 286 & & & 243 & 760 & & \\
\hline III/IV & 1394 & 462 & 932 & & & 272 & 760 & & \\
\hline Tissue type & & & & 0.32 & 0.858 & & & 0.538 & 0.463 \\
\hline Adenocarcinoma & 1551 & 621 & 930 & & & 424 & 1279 & & \\
\hline Non-adenocarcinoma & 484 & 196 & 288 & & & 89 & 243 & & \\
\hline General tumor type & & & & 0.093 & 0.76 & & & 0.516 & 0.473 \\
\hline Ulcerative & 1174 & 468 & 706 & & & 289 & 885 & & \\
\hline Non-ulcerative & 861 & 349 & 512 & & & 224 & 637 & & \\
\hline $\begin{array}{l}\text { Differentiation } \\
\text { degree }\end{array}$ & & & & 2.344 & 0.120 & & & 40.037 & $<0.001$ \\
\hline High/Median & 1291 & 502 & 789 & & & 326 & 1187 & & \\
\hline Low/undifferentiated & 744 & 315 & 429 & & & 188 & 334 & & \\
\hline Tumor location & & & & 1.43 & 0.232 & & & 2.389 & 0.122 \\
\hline Colon & 872 & 337 & 535 & & & 234 & 595 & & \\
\hline Rectum & 1163 & 480 & 683 & & & 379 & 827 & & \\
\hline
\end{tabular}

the esophagus, stomach, liver and pancreas [16, 17]. CEA is secreted by cancer cells resulting in high serum CEA levels.

Many studies have suggested that CEA levels can be used for predicting metastasis although few contradictory reports exist [18-20]. High CEA levels are observed in cancers, whereas changes are also observed in smoking, inflammation, pregnancy, gynecological disease and hepatitis conditions [21, 22]. Furthermore, prognostic potential of pre-post-CEA ratio has been reported for 
Table 2: Multivariate analysis of relationship between pre-operative CEA and pre- to postoperative CEA with clinicopathological parameters of CRC patients

\begin{tabular}{|c|c|c|c|c|c|c|c|c|}
\hline \multirow{3}{*}{ Clinicopathologic characteristics } & \multicolumn{4}{|c|}{ Pre-operative CEA expression } & \multicolumn{4}{|c|}{ Pre- to post-operative CEA ratio } \\
\hline & \multirow[t]{2}{*}{ HR } & \multirow[t]{2}{*}{$P$} & \multicolumn{2}{|c|}{$95 \%$ CI } & \multirow[t]{2}{*}{ HR } & \multirow[t]{2}{*}{$P$ value } & \multicolumn{2}{|c|}{$95 \% \mathrm{CI}$} \\
\hline & & & Lower & Upper & & & Lower & Upper \\
\hline $\begin{array}{l}\text { Tumor family history } \\
\text { Yes vs. No }\end{array}$ & 4.576 & 0.032 & 0.494 & 0.970 & 0.476 & 0.490 & 0.715 & 2.014 \\
\hline $\begin{array}{l}\text { Smoking } \\
\text { Yes vs. No }\end{array}$ & 5.072 & 0.024 & 1.036 & 1.664 & 0.108 & 0.742 & 0.712 & 1.609 \\
\hline $\begin{array}{l}\text { Tumor size (cm) } \\
\geq 5 \mathrm{~cm} \text { vs. }<5 \mathrm{~cm}\end{array}$ & 9.812 & 0.002 & 1.124 & 1.662 & 1.093 & 0.296 & 0.575 & 1.183 \\
\hline $\begin{array}{l}\text { Lymphatic metastasis } \\
\text { Yes vs. No }\end{array}$ & 0.363 & 0.547 & 0.598 & 1.313 & 20.017 & 0.000 & 2.330 & 8.708 \\
\hline $\begin{array}{l}\text { Distant metastasis } \\
\text { Yes vs. No }\end{array}$ & 63.108 & 0.000 & 2.423 & 4.326 & 28.176 & 0.000 & 2.284 & 6.006 \\
\hline $\begin{array}{l}\text { TNM stages } \\
\text { I/II vs. III/IV }\end{array}$ & 9.087 & 0.003 & 0.331 & 0.791 & 28.445 & 0.000 & 3.320 & 13.384 \\
\hline $\begin{array}{l}\text { Tissue type } \\
\text { Adenocarcinoma } \\
\text { vs.। } \\
\text { Non-adenocarcinoma }\end{array}$ & 0.099 & 0.753 & 0.789 & 1.388 & 0.051 & 0.821 & 0.594 & 1.512 \\
\hline $\begin{array}{l}\text { Tumor general type } \\
\text { Ulcerative vs. Non-ulcerative }\end{array}$ & 0.684 & 0.408 & 0.877 & 1.383 & 3.792 & 0.051 & 0.498 & 1.002 \\
\hline $\begin{array}{l}\text { Differentiation degree } \\
\text { High/Median vs. Low/undifferentiated }\end{array}$ & 1.077 & 0.299 & 0.904 & 1.388 & 10.381 & 0.001 & 0.353 & 0.776 \\
\hline $\begin{array}{l}\text { Tumor location } \\
\text { Colon vs. Rectum }\end{array}$ & 0.010 & 0.919 & 0.811 & 1.208 & 1.378 & 0.241 & 0.869 & 1.754 \\
\hline
\end{tabular}

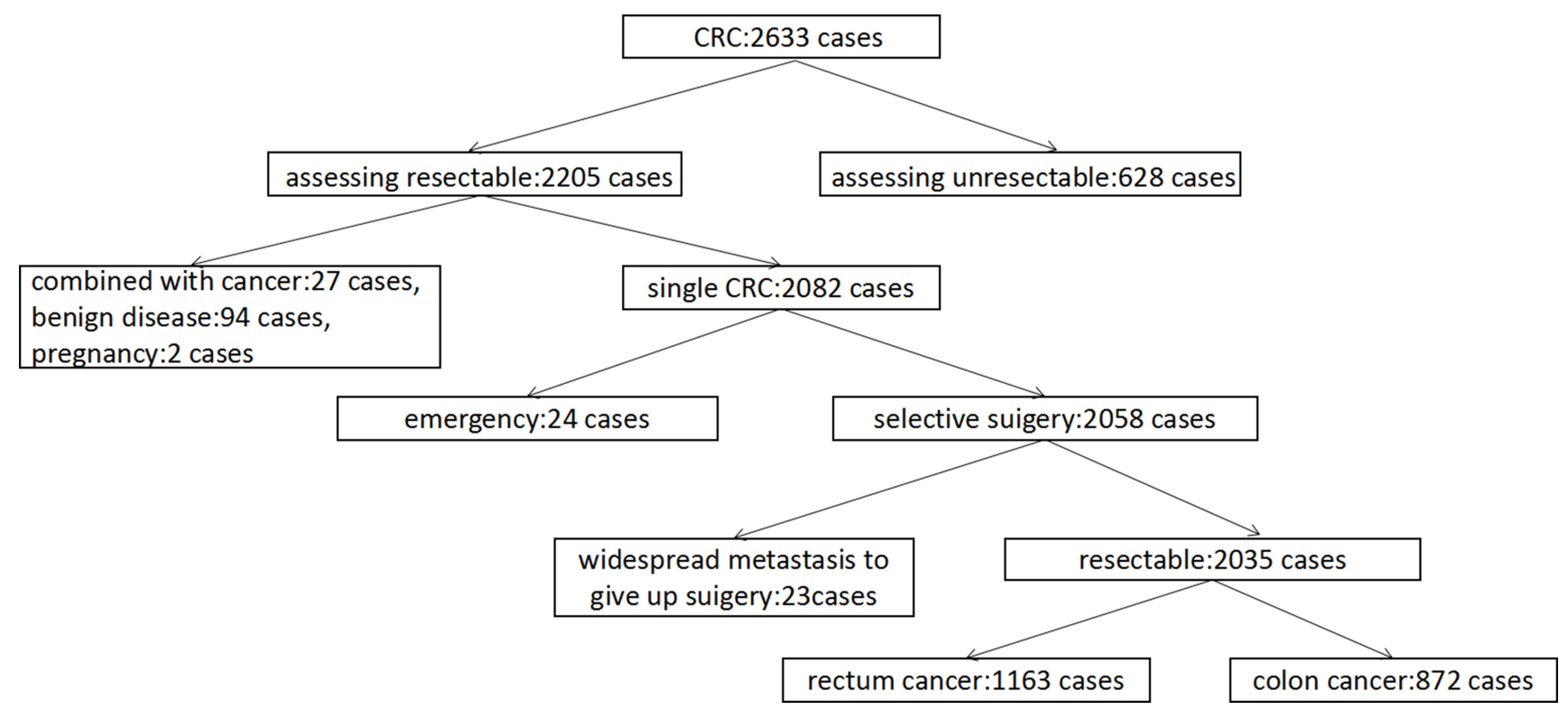

Figure 1: Scheme of selecting research subjects. After screening $2833 \mathrm{CRC}$ cases for eliminating criteria including unresectable tumors, combined with other cancers, benign disease, pregnancy, emergency and widespread metastasis, 2035 CRC cancer patients were chosen for the study. 


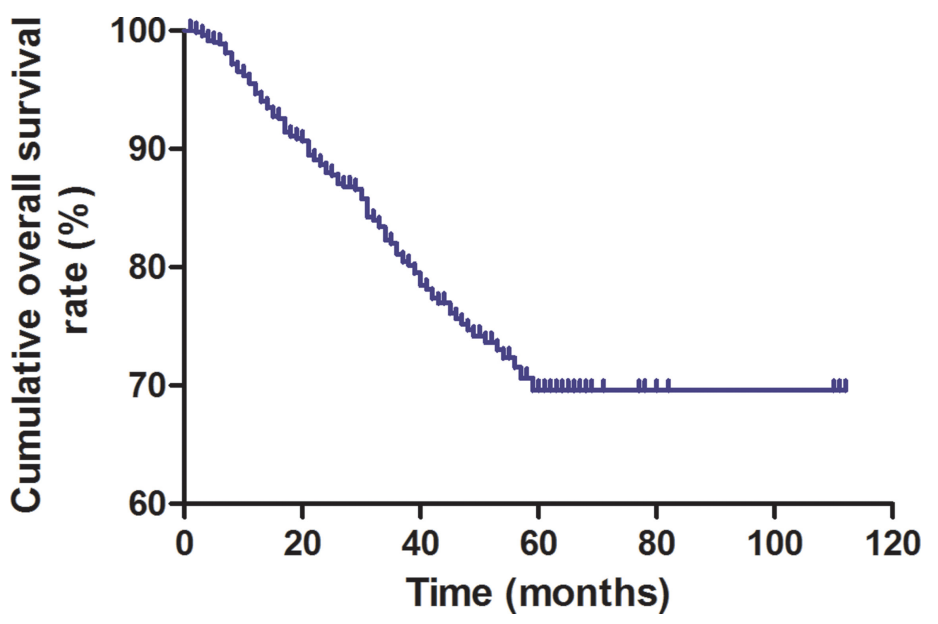

Figure 2: Kaplan-Meier survival curve of enrolled CRC patients. The Kaplan-Meier survival plot shows decreasing overall survival with post-operative time (months).

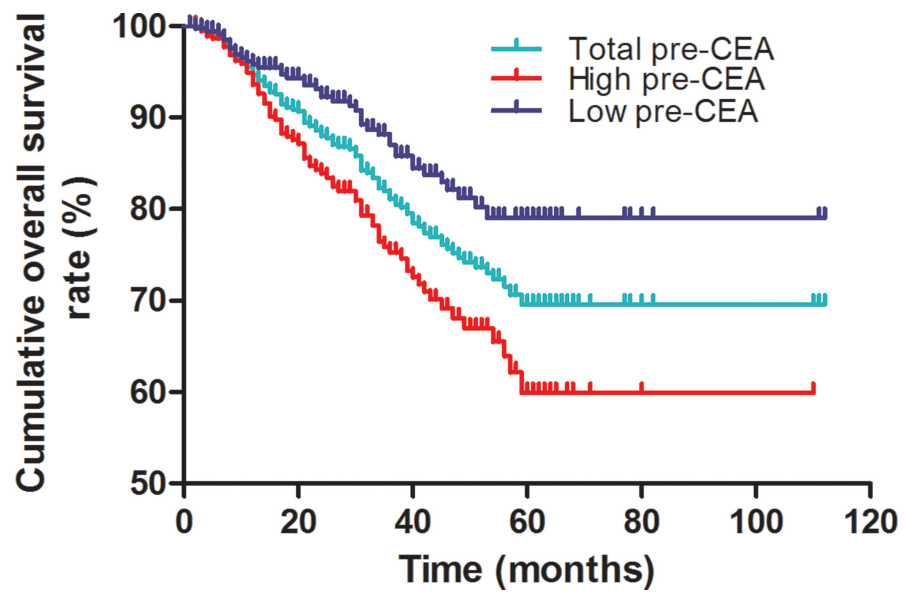

Figure 3: Kaplan-Meier survival curves of CRC patients based on pre-operative CEA levels. Overall survival of CRC patients with high (red) and low (blue) pre-operative CEA levels compared to total (green) CRC patients based on Kaplan-Meier curves and log-rank test. As shown, patients with low pre-CEA levels survived longer than those with high pre-CEA levels $(\log$-rank test, $P<0.001)$.

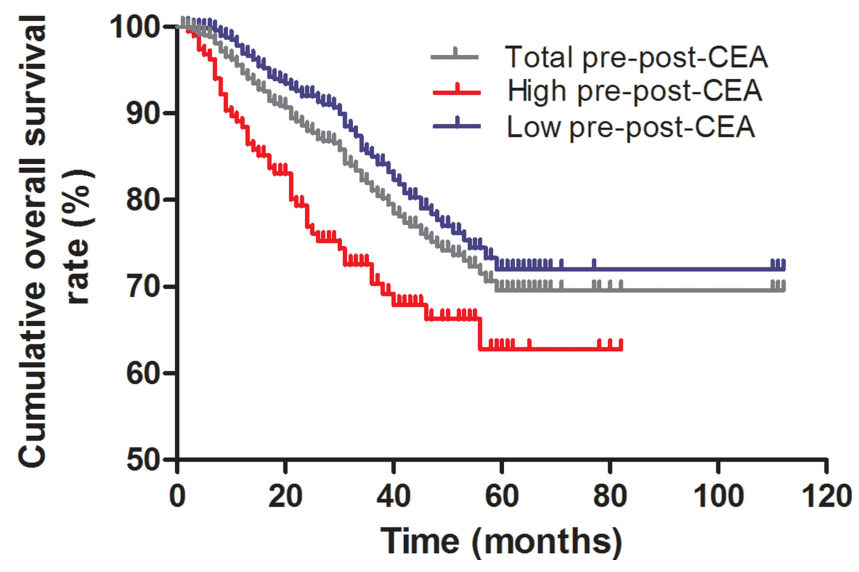

Figure 4: Kaplan-Meier survival curves of CRC patients based on pre-post-CEA ratios. Overall survival of CRC patients with low (blue) and high (red) pre-post-CEA ratios compared to total (gray) number of CRC patients based Kaplan-Meier curves and log rank test. As shown, patients with low pre-post-CEA ratios survived longer than those with high pre-post-CEA ratios (log-rank test, $P<$ 0.001). 
Table 3: Univariate analyses of correlation between clinicopathological parameters and 5-year OS of CRC patients

\begin{tabular}{|c|c|c|c|c|}
\hline Clinicopathologic characteristics & $n$ & 5-year OS & $\mathrm{X}^{2}$ & $P$ value \\
\hline Gender & & & 0.384 & 0.535 \\
\hline Male & 1138 & $72.2 \%$ & & \\
\hline Female & 897 & $66.7 \%$ & & \\
\hline Age (Years) & & & 0.046 & 0.831 \\
\hline$\geq 60$ & 1091 & $69.5 \%$ & & \\
\hline$<60$ & 944 & $69.9 \%$ & & \\
\hline Family history & & & 0.000 & 0.997 \\
\hline Yes & 173 & $68.3 \%$ & & \\
\hline No & 1862 & $69.7 \%$ & & \\
\hline Smoking & & & 10282 & 0.258 \\
\hline Yes & 426 & $75.4 \%$ & & \\
\hline No & 1609 & $67.8 \%$ & & \\
\hline Pre-CEA levels & & & 13.849 & $<0.001$ \\
\hline high & 1218 & $60 \%$ & & \\
\hline low & 817 & $79.1 \%$ & & \\
\hline Pre-post-CEA ratio & & & 14.513 & $<0.001$ \\
\hline Low & 578 & $62.8 \%$ & & \\
\hline High & 195 & $72 \%$ & & \\
\hline Tumor size (cm) & & & 5.526 & 0.019 \\
\hline$\geq 5 \mathrm{~cm}$ & 945 & $60.7 \%$ & & \\
\hline$<5 \mathrm{~cm}$ & 990 & $76.1 \%$ & & \\
\hline Lymphatic metastasis & & & 6.353 & 0.012 \\
\hline Yes & 1024 & $64.2 \%$ & & \\
\hline No & 1011 & $72 \%$ & & \\
\hline Distant metastasis & & & 122.546 & $<0.001$ \\
\hline Yes & 615 & $27.4 \%$ & & \\
\hline No & 1420 & $78.2 \%$ & & \\
\hline TNM stage & & & 4.781 & 0.029 \\
\hline $\mathrm{I} / \mathrm{II}$ & 641 & $71.6 \%$ & & \\
\hline III/IV & 1394 & $65.2 \%$ & & \\
\hline Tissue type & & & 0.858 & 0.354 \\
\hline Adenocarcinoma & 1551 & $69.5 \%$ & & \\
\hline Non-adenocarcinoma & 484 & $70.1 \%$ & & \\
\hline \multicolumn{5}{|l|}{ Tumor general type } \\
\hline Ulcerative & 1174 & $67.4 \%$ & 0.976 & 0.269 \\
\hline Non-ulcerative & 861 & $71.2 \%$ & & \\
\hline Differentiation degree & & & 6.238 & 0.013 \\
\hline High/Median & 1291 & $70.4 \%$ & & \\
\hline Low/undifferentiated & 744 & $64.5 \%$ & & \\
\hline Tumor location & & & 0.026 & 0.872 \\
\hline Colon & 872 & $71.8 \%$ & & \\
\hline Rectum & 1163 & $68.3 \%$ & & \\
\hline
\end{tabular}


CRC patients. In gastric cancer, elevated pre-operative CK19 and CEA mRNA levels were associated with lymph node metastasis and predicted poor prognosis [22]. Yang et al. also reported that elevated pre- and post-operative serum CEA levels were associated with recurrence and poor clinical outcomes in few CRC patients [23]. Duan et al showed that high serum CEA or CYFRA 21-1 levels before and after surgery were associated with poor overall survival (OS) and progress-free survival (PFS) in stage I non-small cell lung cancer [11]. In this study, we explored the prognostic significance of pre-post-CEA ratios for CRC patients. We observed that pre-post-CEA ratios were closely related with smoking, tumor size, lymph node and distant metastases and post-operative pathological TNM staging. Also, our analysis demonstrated that distant metastasis and post-operative TNM stage were independent risk factors along with pre-CEA levels and pre-post-CEA ratios, consistent with previous reports.

Lymph node metastasis [24] and distant metastasis, particularly liver $[25,26]$ are independent risk factors with pre-CEA levels for CRC. The cell recognition, adhesion and immunosuppressive properties of CEA, which are $\mathrm{Ca} 2+$ dependent cell adhesion molecules aids aggregation, adhesion, invasion and metastasis of tumor cells $[27,28]$. Therefore, excessive serum CEA levels are beneficial to CRC metastasis. Our study also demonstrated that lymphatic and distant metastases were independent risk factors in advanced stage III and IV CRC.

In previous studies, pre-CEA levels were identified as reliable indicators of prognosis and therapeutic efficacy in stage II and III CRC patients [18, 29]. Many studies also reported that pre-CEA levels were an independent risk factor for CRC patients [18, 30-31]. Our study further confirmed that pre-CEA level was an independent prognostic factor. Therefore, pre-CEA levels can be used evaluate therapeutic efficacy, post-operative tumor recurrence and predict prognosis of CRC patients.

Apart from the prognostic value of pre-CEA levels, few studies have also reported the prognostic value of preoperative and post-operative CEA levels in combination [10]. Therefore, we analyzed the significance of pre-postCEA ratios and found that it was associated with lymphatic and distant metastases and post-operative pathological TNM stage. These three indicators were also shown to be independent risk factors along with pre-post-CEA ratios.

Based on tumor source, the degree of malignancy determined by histology has been used to classify different pathological types of tumors $[32,33]$. Most CRC patients are associated with moderately differentiated tumors, whereas high CEA levels are associated with poorly differentiated or undifferentiated CRC that are highly malignant [34]. In our study, pre-operative serum CEA levels were higher in lowly differentiated and undifferentiated carcinomas. Further, the differentiation degree of tumors affected the pre-post-CEA ratios in CRC patients. CEA is an important risk factor affecting $\mathrm{CRC}$ prognosis [13]. We observed that patients with decreasing post-operative CEA demonstrated better prognosis than those with higher post-operative CEA. Therefore, prepost-CEA ratio is potentially an important prognostic marker.

During malignant transformation of CRC cells, overexpression of CEA lowers the function of other adhesion molecules and interferes in the interaction between normal cells, thereby weakening the singlelayer structure of glandular tube [27-35, 36]. Therefore, excessive CEA in combination with genetic damage would promote malignancy of tumors. According to the NCCN guidelines, CRC of TNM stages 3 and 4 are accompanied by lymphatic and distant metastases, severely damaged

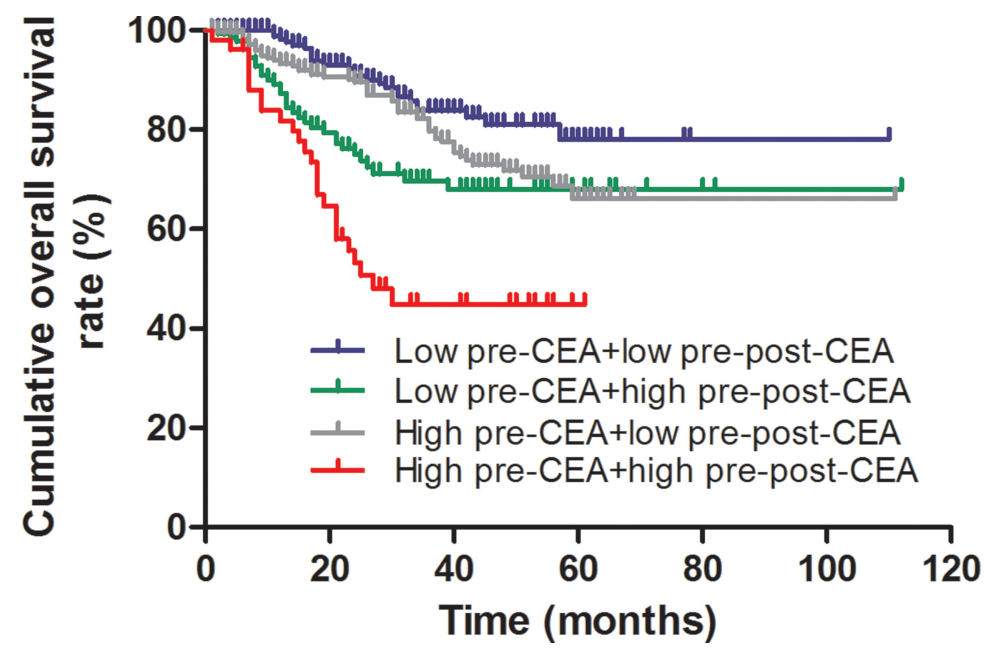

Figure 5: Kaplan-Meier survival curve analysis of different combinations of pre-CEA levels and pre-post-CEA ratios. CRC patients with low pre-CEA levels plus low pre-post-CEA ratio (blue) survived longer than those with high pre-CEA levels plus high pre-post-CEA ratios (red). CRC patients with low pre-CEA levels plus high pre-post-CEA ratios (green) and those with high pre-CEA levels plus low pre-post-CEA ratios (gray) show comparable survival rates (log-rank test, $P>0.05$ ) and are intermediate in comparison to the previous two groups (log-rank test, all $P>0.05$ ). 
Table 4: COX regression survival analyses of clinicopathological parameters of CRC patients

\begin{tabular}{|c|c|c|c|c|}
\hline \multirow[t]{2}{*}{ Clinicopathological characteristics } & \multirow[t]{2}{*}{$\mathbf{R R}$} & \multirow[t]{2}{*}{$P$ value } & \multicolumn{2}{|c|}{$95 \%$ confidence interval } \\
\hline & & & Lower & Upper \\
\hline $\begin{array}{l}\text { Gender } \\
\text { Male vs. Female }\end{array}$ & 0.591 & 0.442 & 0.786 & 1.738 \\
\hline $\begin{array}{l}\text { Age (Years) } \\
\geq 60 \text { vs. }<60\end{array}$ & 2.536 & 0.111 & 0.511 & 1.072 \\
\hline $\begin{array}{l}\text { Tumor family history } \\
\text { Yes vs. No }\end{array}$ & 0.043 & 0.835 & 0.618 & 1.815 \\
\hline $\begin{array}{l}\text { Smoking } \\
\text { Yes vs. No }\end{array}$ & 0.046 & 0.831 & 0.636 & 1.758 \\
\hline $\begin{array}{l}\text { Pre-CEA } \\
\geq 5 \text { vs. }<5\end{array}$ & 7.897 & 0.005 & 0.351 & 0.830 \\
\hline $\begin{array}{l}\text { Pre-post-CEA } \\
\text { Low vs. High }\end{array}$ & 5.434 & 0.020 & 0.390 & 0.922 \\
\hline $\begin{array}{l}\text { Tumor size (cm) } \\
\geq 5 \mathrm{~cm} \text { vs. }<5 \mathrm{~cm}\end{array}$ & 2.581 & 0.108 & 0.485 & 1.074 \\
\hline $\begin{array}{l}\text { Lymphatic metastasis } \\
\text { Yes vs. no }\end{array}$ & 0.093 & 0.761 & 0.512 & 1.631 \\
\hline $\begin{array}{l}\text { Distant metastasis } \\
\text { Yes vs. no }\end{array}$ & 28.112 & 0.000 & 0.177 & 0.451 \\
\hline $\begin{array}{l}\text { TNM stage } \\
\text { I/II vs. III/IV }\end{array}$ & 4.420 & 0.036 & 1.054 & 4.540 \\
\hline $\begin{array}{l}\text { Tissue type } \\
\text { Adenocarcinoma } \\
\text { vs. Non-adenocarcinoma }\end{array}$ & 0.568 & 0.451 & 0.471 & 1.398 \\
\hline $\begin{array}{l}\text { Tumor general type } \\
\text { Ulcerative vs. Non-ulcerative }\end{array}$ & 1.640 & 0.200 & 0.884 & 1.801 \\
\hline $\begin{array}{l}\text { Differentiation degree } \\
\text { High/Median } \\
\text { vs. Low/undifferentiated }\end{array}$ & 10.181 & 0.001 & 1.272 & 2.741 \\
\hline $\begin{array}{l}\text { Tumor location } \\
\text { Colon vs. Rectum }\end{array}$ & 0.003 & 0.959 & 0.697 & 1.463 \\
\hline
\end{tabular}

colon tissues and CEA overexpression. Therefore, high pre-CEA levels and lymphatic or distant metastases were used as prognostic indicators and lymph node or microdistant metastasis was neglected during surgery [37]. After surgery, post-CEA levels would increase leading to high pre-post-CEA ratios. In our study, pre-post-CEA ratio was closely related with lymphatic and distant metastases, TNM stage and degree of tumor differentiation, consistent with previous reports.

There is consensus that lymphatic metastasis, distant metastasis and TNM stage dictate prognostic status of CRC patients. In our study, these three indicators were also independent risk factors in relation to for pre-post-CEA ratios. Therefore, pre-post-CEA ratios are an essential risk factor for prognosis of CRC patients.

In conclusion, pre-post-CEA ratios were associated with the malignant phenotype of lymphatic metastasis, distant metastasis, TNM stage and degree of tumor differentiation in CRC patients. It was also an independent risk factor for CRC patients. Therefore, we postulate that pre-post-CEA ratio is a potential tumor biomarker to evaluate prognosis and therapeutic efficacy in CRC patients.

\section{MATERIALS AND METHODS}

\section{Patients and clinicopathological parameters}

This study was approved by the Ethics Committee of the First Affiliated Hospital of Zhengzhou University (No. ZZUF-2016174). All patients provided informed written consent prior to their participation. Clinicopathological parameters and follow-up data were obtained 2035 CRC patients (1138 male, 897 female) that received radical surgery in the First Affiliated Hospital of Zhengzhou University between June 2001 and June 2011. The mean 
patient age was $59.84+13.44$ years. Among the 2035 CRC patients, 872 had colon cancer and 1163 rectal cancers. Colon cancer diagnosis was confirmed by histopathology prior to their participation. None of the enrolled patients received pre-operative chemotherapy or immunotherapy. Tumor-node-metastasis (TNM) stage was determined according to the American Joint Committee on Cancer/ International Union Against Cancer TNM staging system of colorectal cancer (2010, 7 th edition).

\section{Enzyme linked immunosorbent assay (ELISA) assay}

Blood samples ( $4 \mathrm{ml}$ each) were obtained within the week before surgery for preoperative CEA estimation and 1-2 weeks after the surgery for post-operative CEA estimation. Serum CEA levels were estimated by ELISA kit (ab183365, Abcam, England) according to manufacturer's instructions.

\section{Patient follow-up}

After surgery, the patients were assessed once a month for the first 6 months, once every 3 months for the first 2 years, once every 6 months until 5 years followed by once a year. Follow-ups were either by outpatient or inpatient review or by telephone. 216 patients did not participate in the follow-up analyses because they did not communicate with the physicians after surgery. In addition, 13 patients developed dysthymia and were unable to cooperate with the study; 3 patients committed suicide and 19 patients did not participate in the follow-up for unknown reasons. Therefore, the total follow-up rate in the study was $87.67 \%$.

\section{Chemotherapy and radical surgery}

FOLFOX6 was used as the first line adjuvant or neoadjuvant therapy scheme for CRC patients with high-risk IInd or IIIrd stage. CapeOX was used as the chemotherapy scheme as either 1 st or 2 nd line adjuvant or neoadjuvant therapy for CRC patients with high-risk IInd, IIIrd or IVth stage, drug resistance or postoperative recurrence. FOLFIRI was used as the chemotherapy scheme for CRC patients in advanced IVth stage, postoperative recurrence, metastasis or drug resistance.

Radical surgery was performed according to complete mesocolic excision (CME) for colon cancer patients and total mesorectal excision (TME) principle for rectal cancer patients.

\section{Statistical analysis}

All statistical analyses were carried out using SPSS for Windows version 20 (SPSS Inc., Chicago, IL, United States). Univariate analysis was performed by $\chi^{2}$ test to analyze pre-CEA levels and pre-post-CEA ratios and clinicopathological parameters. Kaplan Meier survival curves and log-rank test were used to compare the low and high level groups of pre-CEA levels and pre-post-CEA ratios. Multivariate survival analysis was performed by the Cox regression model to determine relative risk (RR) and $95 \%$ confidence intervals (CI). Statistical significance was defined as $P<0.05$.

\section{ACKNOWLEDGMENTS AND FUNDING}

The authors thank all the individuals who assisted with this study.

\section{CONFLICTS OF INTEREST}

The authors declare that they have no conflicts of interest.

\section{REFERENCES}

1. Chen W, Zheng R, Baade PD, Zhang S, Zeng H, Bray F, Jemal A, Yu XQ, He J. Cancer statistics in China, 2015. CA Cancer J Clin. 2016; 66:115-32.

2. Siegel RL, Fedewa SA, Anderson WF, Miller KD, Ma J, Rosenberg PS, Jemal A. Colorectal Cancer Incidence Patterns in the United States, 1974-2013. J Natl Cancer Inst. 2017; 109. https://doi.org/10.1093/jnci/djw322.

3. Vidigal VM, Silva TD, de Oliveira J, Pimenta CA, Felipe AV, Forones NM. Genetic polymorphisms of vitamin D receptor (VDR), CYP27B1 and CYP24A1 genes and the risk of colorectal cancer. Int J Biol Markers. 2017; 32:e224-e230.

4. Chow D, Stabile BE, Lee B. Efficacy of robotic-assisted surgery in colorectal cancer: A systematic review and metaanalysis. J Clin Oncol. 2011; 29:e14125.

5. Pulte D, Jansen L, Brenner H. Social disparities in survival after diagnosis with colorectal cancer: contribution of race and insurance status. Cancer Epidemiol. 2017; 48:41-47.

6. Frouws MA, van Herk-Sukel MP, Maas HA, Van de Velde CJ, Portielje JE, Liefers GJ, Bastiaannet E. The mortality reducing effect of aspirin in colorectal cancer patients: interpreting the evidence. Cancer Treat Rev. 2017; 55:120-27.

7. Zhang F, Zhang Y, Zhao W, Deng K, Wang Z, Yang C, Ma L, Openkova MS, Hou Y, Li K. Metabolomics for biomarker discovery in the diagnosis, prognosis, survival and recurrence of colorectal cancer: a systematic review. Oncotarget. 2017; 8:35460-35472. https://doi.org/10.18632/ oncotarget.16727.

8. Das V, Kalita J, Pal M. Predictive and prognostic biomarkers in colorectal cancer: A systematic review of recent advances and challenges. Biomed Pharmacother. 2017; 87:8-19.

9. Tsai PL, Su WJ, Leung WH, Lai CT, Liu CK. Neutrophillymphocyte ratio and CEA level as prognostic and predictive factors in colorectal cancer: A systematic review and meta-analysis. J Cancer Res Ther. 2016; 12:582-89. 
10. Hotta T, Takifuji K, Yokoyama S, Matsuda K, Oku Y, Nasu T, Ieda J, Yamamoto N, Iwamoto H, Takei Y, Mizumoto Y, Yamaue H. Impact of the post/preoperative serum CEA ratio on the survival of patients with rectal cancer. Surg Today. 2014; 44:2106-15.

11. Duan X, Cui Y, Li H, Shi G, Wu B, Liu M, Chang D, Wang T, Kong Y. High preoperative and postoperative levels of carcinoembryonic antigen and CYFRA 21-1 indicate poor prognosis in patients with pathological Stage I nonsmall cell lung cancer. Indian J Cancer. 2015; 52:E158-63.

12. Araujo RL, Gönen M, Allen P, DeMatteo R, Kingham P, Jarnagin W, D'Angelica M, Fong Y. Positive postoperative CEA is a strong predictor of recurrence for patients after resection for colorectal liver metastases. Ann Surg Oncol. 2015; 22:3087-93.

13. Lin JK, Lin CC, Yang SH, Wang HS, Jiang JK, Lan YT, Lin TC, Li AF, Chen WS, Chang SC. Early postoperative CEA level is a better prognostic indicator than is preoperative CEA level in predicting prognosis of patients with curable colorectal cancer. Int J Colorectal Dis. 2011; 26:1135-41.

14. Chau I, Allen MJ, Cunningham D, Norman AR, Brown G, Ford HE, Tebbutt N, Tait D, Hill M, Ross PJ, Oates $\mathrm{J}$. The value of routine serum carcino-embryonic antigen measurement and computed tomography in the surveillance of patients after adjuvant chemotherapy for colorectal cancer. J Clin Oncol. 2004; 22:1420-29.

15. Wallin U, Rothenberger D, Lowry A, Luepker R, Mellgren A. CEA - a predictor for pathologic complete response after neoadjuvant therapy for rectal cancer. Dis Colon Rectum. 2013; 56:859-68.

16. Wichmann MW, Müller C, Lau-Werner U, Strauss T, Lang RA, Hornung HM, Stieber P, Schildberg FW. The role of carcinoembryonic antigen for the detection of recurrent disease following curative resection of large-bowel cancer. Langenbecks Arch Surg. 2000; 385:271-75.

17. Verberne CJ, Zhan Z, van den Heuvel ER, Oppers F, de Jong AM, Grossmann I, Klaase JM, de Bock GH, Wiggers T. Survival analysis of the CEAwatch multicentre clustered randomized trial. Br J Surg. 2017; 104:1069-77.

18. Yoshikawa M, Morine Y, Ikemoto T, Imura S, Higashijima J, Iwahashi S, Saito YU, Takasu C, Yamada S, Ishikawa D, Teraoku H, Takata A, Yoshimoto T, et al. Elevated Preoperative Serum CEA Level Is Associated with Poor Prognosis in Patients with Hepatocellular Carcinoma Through the Epithelial-Mesenchymal Transition. Anticancer Res. 2017; 37:1169-75.

19. Liu CC, Yang H, Zhang R, Zhao JJ, Hao DJ. Tumourassociated antigens and their anti-cancer applications. Eur J Cancer Care (Engl). 2016 Feb 7. doi: 10.1111/ecc.12446. [Epub ahead of print].

20. Sun Z, Zhang N. Clinical evaluation of CEA, CA199, CA72-4 and CA125 in gastric cancer patients with neoadjuvant chemotherapy. World J Surg Oncol. 2014; 12:397.
21. Liska V, Treska V, Skalicky T, Fichtl J, Bruha J, Vycital O, Topolcan O, Palek R, Rosendorf J, Polivka J, Holubec L. Evaluation of Tumor Markers and Their Impact on Prognosis in Gallbladder, Bile Duct and Cholangiocellular Carcinomas - A Pilot Study. Anticancer Res. 2017; 37:2003-09.

22. Qiao YF, Chen CG, Yue J, Ma MQ, Ma Z, Yu ZT. Prognostic significance of preoperative and postoperative CK19 and CEA mRNA levels in peripheral blood of patients with gastric cardia cancer. World J Gastroenterol. 2017; 23:1424-33.

23. Yang KM, Park IJ, Kim CW, Roh SA, Cho DH, Kim JC. The prognostic significance and treatment modality for elevated pre- and postoperative serum CEA in colorectal cancer patients. Ann Surg Treat Res. 2016; 91:165-71.

24. Yeung TM, Buskens C, Wang LM, Mortensen NJ, Bodmer WF. Myofibroblast activation in colorectal cancer lymph node metastases. Br J Cancer. 2013; 108:2106-15.

25. Ismaiel NE, Sharaf WM, Helmy DO, Zaki MM, Badawi MA, Soliman AS. Detection of Cancer Stem Cells in Colorectal Cancer: Histopathological and Immunohistochemical Study. Open Access Maced J Med Sci. 2016; 4:543-47.

26. Wang Y, Duan B, Shen C, Wu B, Luo J, Zhao G. Treatment and multivariate analysis of colorectal cancer with liver metastasis. Hepatogastroenterology. 2014; 61:1568-73.

27. Wang X, Yang Z, Tian H, Li Y, Li M, Zhao W, Zhang C, Wang T, Liu J, Zhang A, Shen D, Zheng C, Qi J, et al. Circulating MIC-1/GDF15 is a complementary screening biomarker with CEA and correlates with liver metastasis and poor survival in colorectal cancer. Oncotarget. 2017; 8:24892-24901. https://doi.org/10.18632/oncotarget.15279.

28. Yan C, Hu Y, Zhang B, Mu L, Huang K, Zhao H, Ma C, Li $\mathrm{X}$, Tao D, Gong J, Qin J. The CEA-/lo colorectal cancer cell population harbors cancer stem cells and metastatic cells. Oncotarget. 2016; 7:80700-15. https://doi.org/10.18632/ oncotarget.13029.

29. Hashiguchi Y, Kasai M, Fukuda T, Ichimura T, Yasui T, Sumi T. Serum carcinoembryonic antigen as a tumour marker in patients with endometrial cancer. Curr Oncol. 2016; 23:e439-42.

30. Lee JS, Park S, Park JM, Cho JH, Kim SI, Park BW. Elevated levels of preoperative CA 15-3 and CEA serum levels have independently poor prognostic significance in breast cancer. Ann Oncol. 2013; 24:1225-31.

31. Li Destri G, Rubino AS, Latino R, Giannone F, Lanteri R, Scilletta B, Di Cataldo A. Preoperative carcinoembryonic antigen and prognosis of colorectal cancer. An independent prognostic factor still reliable. Int Surg. 2015; 100:617-25.

32. Yang M, Rehman AU, Zuo C, Sheehan CE, Lee EC, Lin J, Zhao Z, Choi E, Lee H. A novel histologic grading scheme based on poorly differentiated clusters is applicable to treated rectal cancer and is associated with established histopathological prognosticators. Cancer Med. 2016; 5:1510-18. 
33. Kim JE, Lee JM, Baek JH, Moon SK, Kim SH, Han JK, Choi BI. Differentiation of poorly differentiated colorectal adenocarcinomas from well- or moderately differentiated colorectal adenocarcinomas at contrast-enhanced multidetector CT. Abdom Imaging. 2015; 40:1-10.

34. Wang N, Chen Y, Yang X, Jiang Y. Selenium-binding protein 1 is associated with the degree of colorectal cancer differentiation and is regulated by histone modification. Oncol Rep. 2014; 31:2506-14.

35. Stojkovic Lalosevic M, Stankovic S, Stojkovic M, Markovic V, Dimitrijevic I, Lalosevic J, Petrovic J, Brankovic M, Pavlovic Markovic A, Krivokapic Z. Can preoperative CEA and CA19-9 serum concentrations suggest metastatic disease in colorectal cancer patients? Hell J Nucl Med. 2017; 20:41-45.
36. Yu D, An G, Xu L. Investigation of Efficacy Evaluation Comparison of cfDNA and CEA in Colorectal Cancer. Clin Lab. 2016; 62:1947-53.

37. Zhao R, Cai Z, Li S, Cheng Y, Gao H, Liu F, Wu S, Liu S, Dong Y, Zheng L, Zhang W, Wu X, Yao X. Expression and clinical relevance of epithelial and mesenchymal markers in circulating tumor cells from colorectal cancer. Oncotarget. 2017; 8:9293-302. https://doi.org/10.18632/ oncotarget. 14065 . 